\title{
Common risk factors for changes in body weight and psychological well-being in Japanese male middle-aged workers
}

\author{
Takiko Sagara · Yoshiaki Hitomi · Yasuhiro Kambayashi · \\ Yuri Hibino · Ichiyo Matsuzaki · Shinichiro Sasahara · \\ Keiki Ogino $\cdot$ Kotaro Hatta $\cdot$ Hiroyuki Nakamura
}

Received: 19 February 2009/Accepted: 12 July 2009/Published online: 5 August 2009

(C) The Japanese Society for Hygiene 2009

\begin{abstract}
Objectives Overweight and poor psychological wellbeing are becoming serious health issues in the Japanese workplace. Concurrence of those physical and mental conditions has been pointed out, especially in middle-aged workers. Therefore, we tried to determine common risk factors for body weight gain and the deterioration of psychological well-being in male middle-aged office workers using a five-year follow-up study.

Methods We administered General Health Questionnaire12 (GHQ-12) as an indicator of psychological well-being to 110 male workers with ages ranging from 40-59 years, and analyzed the influence of several psychological factors, namely sense of coherence (SOC), health locus of control (HLC), and lifestyle variables such as exercise frequency, alcohol intake, smoking status, and dietary intake on changes of body mass index and GHQ-12 score.
\end{abstract}

T. Sagara · Y. Hitomi · Y. Kambayashi · Y. Hibino ·

H. Nakamura $(\square)$

Department of Environmental and Preventive Medicine,

Graduate School of Medical Science, Kanazawa University,

Kanazawa, Japan

e-mail: hiro-n@po.incl.ne.jp

I. Matsuzaki · S. Sasahara

Institute of Community Medicine, University of Tsukuba,

Tsukuba, Japan

\section{K. Ogino}

Department of Public Health,

Okayama University Graduate School of Medicine,

Dentistry and Pharmaceutical Sciences,

Okayama, Japan

K. Hatta

Department of Psychiatry,

Juntendo University School of Medicine,

Tokyo, Japan
Results McNemar's chi-squared test showed significant concurrence of weight gain and deterioration of psychological well-being after five-year follow-up. Low-SOC score, low frequency of exercise, and high-dietary intake at supper were significantly associated with both weight gain and poorer psychological well-being in workers, results which were supported by multiple regression analysis.

Conclusions These results suggest that exercise and calorie restriction seem to prevent weight gain and promote psychological well-being in workers. Low SOC, which implies difficulty in coping with stress, may be an important risk factor not only for deterioration of psychological well-being but also for becoming overweight. These assumptions must be confirmed by conducting future intervention studies on SOC and lifestyle including exercise and eating behavior.

Keywords Body weight - Exercise - Diet . General Health Questionnaire-12 - Sense of coherence . Workers

\section{Introduction}

The human population has slowly transformed from the "hunter-gatherer" period to the current environment of high energy consumption, minimal physical activity, and a lifestyle that includes stress and anxiety [1]. Obesity and overweight are also serious health issues worldwide. Throughout the world, including Asian countries, over 300 million people are obese and an additional billion are overweight $[1,2]$. Obesity is an important cause of excess mortality and morbidity of various diseases such as diabetes mellitus and cardiovascular disease [3, 4]. Although weight gain is principally the consequence of positive energy 
balance [5, 6], involvement of psychological factors remains to be clarified well $[7,8]$.

In the working population, poor adaptability to new tasks, an increase in the complexities of human relationships, and, in Japan, the collapse of the lifetime employment system, have led to the deterioration of mental health. Mental health is an important component of occupational health, and the National Institute for Occupation and Safety (NIOSH) recognizes psychological disorders as work-related diseases and injuries [9]. Therefore, it is an urgent task to study the ideal work environment for workers, and their psychological well-being, to improve the mental health condition of workers. This is considered to be an exceedingly important problem in our society $[10,11]$.

Recent studies have showed a concurrence of obesity or overweight with psychological problems, including stress, affective, and anxiety symptoms [7, 12, 13]. Obesity as such has also been related to cognitive impairment [14]. Therefore, it is very important to examine the risk factors which are common in the development of both weight gain and poor psychological well-being in workers.

To address such recent health problems in the workplace, in this study, we used our model in which changes in body weight and psychological well-being in workers are influenced by psychological and behavioral factors. Therefore, we analyzed how psychological factors, including sense of coherence (SOC) and health locus of control (HLC), and behavioral factors such as smoking, exercise habits, and dietary intake, are related to the change in body mass index (BMI) and answers to General Health Questionnaire-12 (GHQ-12) as indicators of weight gain and psychological well-being, respectively, using a longitudinal study with a five-year follow-up for male office workers.

\section{Subjects and methods}

\section{Subjects}

One-hundred and thirty-one male office workers aged 40-59 years old, who were recruited from three corporations, namely, a computer service enterprise, a computer store, and an electrical equipment enterprise in Ishikawa and Toyama Prefectures in Japan, participated in this study during 2000-2002 and were followed-up for five years. Ten workers, who had history of use of medical drugs or history of hypertension, hyperlipidemia, diabetes mellitus, or angina pectoris, were excluded in this study. The 121 workers who gave their written informed consent regarding this study were $83.4 \%$ of all 145 male office workers aged 40-59 years old belonged to the three corporations. During the period, eleven workers dropped out of this study because of retirement (six workers) or disagreement in midstream (five workers). Final participants in this study consisted of 110 male office workers with ages ranging from 40 to 59 years old (mean age \pm standard deviation (SD), $52.4 \pm 2.75$ years). There were no statistically significant differences in any indicators at baseline between the 110 participants and 11 dropouts. The subjects completed several self-administered questionnaires regarding their psychological well-being. They included GHQ-12, SOC, perceived stress, and the health locus of control (HLC). In addition to completing psychological questionnaires, they also completed a self-administered questionnaire regarding their lifestyles that included exercise, alcohol drinking habits, smoking status, dietary intake, and body mass index (BMI, $\mathrm{kg} / \mathrm{m}^{2}$ ) as an indicator of body weight increase.

At the end of five-year follow-up period, BMI and GHQ-12 for the 110 workers were examined in the same manner as described above. This study was approved by the Ethics Committee on Experimentation of Kanazawa University, Takara-machi Campus.

\section{GHQ-12}

GHQ-12, which is a modified shorter version of the original 60-item questionnaire, was used to assess psychological well-being. Each item response in GHQ-12 was scored as 0-0-1-1 using a bi-modal method, with total score ranging from 0 to 12 points. High scores indicate poor psychological well-being. GHQ, which was developed by Goldberg in the UK $[15,16]$, is a self-administered screening questionnaire, designed to detect current diagnosable changes in mental health status and used to identify cases of potential mental disorders. GHQ is also used for primary health care screening in general population surveys or in general medical practice $[15,16]$. The validation of a shortened version of GHQ-12 as a measure of psychological well-being is well documented $[15,16]$.

\section{SOC}

A Japanese version of the SOC questionnaire, which was translated from the original SOC questionnaire [17] by Yamazaki [18], was used. SOC has been described as a global orientation system that expresses the extent to which one has a persistent, enduring, yet dynamic feeling of confidence that:

1 the stimuli, derived from one's internal and external environments in the course of living are structured, predictable, and explicable;

2 resources are available to one for meeting the demands posed by these stimuli; and 
3 such demands are challenges, worthy of investment and engagement [17].

The three components in the SOC construct are comprehensibility, manageability and meaningfulness. The 29item questionnaire of SOC used in this study ranged from a minimum of 29 to a maximum of 203 points. The lower the SOC score, the poorer was one's psychological attitude to SOC.

Perceived stress scale

The 14-item perceived stress scale described by Cohen et al. [19] was used to assess the degree to which various situations in life were perceived as stressful. Items on the perceived stress scale were designed to measure the degree to which the subjects felt their lives were unpredictable, uncontrollable, and overwhelming [19, 20]. A high score on the stress index indicates a greater degree of stress.

\section{HLC}

HLC assessment was performed using the Japanese version of HLC in which Horige [21] had modified the multidimensional HLC scales described by Wallston et al. [22]. The Japanese version of HLC was designed to measure five separate dimensions of the locus of control beliefs related to health behavior for Japanese people: internal (I), professional (P), family: $(F)$, chance $(\mathrm{C})$, and supernatural $(\mathrm{S})$ HLCs. Each HLC contains five items and each item was scored from 1 to 6 points.

\section{Lifestyles}

Physical exercise habits, alcohol drinking, and smoking habits were also assessed by use of self-administered questionnaires. The responses to the physical exercise frequency were classified as never (less than one day, 2 points), a few days (2-3 days, 1 point), and always (more than four days, 1 point) per week. Mild exercise, equivalent to 30 min walking was regarded as a form of physical exercise in the questionnaire. The responses to alcohol drinking frequency were scored from 1 to 2 as never (1 point), sometimes (1 point), and every day (2 points). According to their frequency of cigarette smoking, subjects were coded as current smokers ( 2 points), nonsmokers (1 point), and ex-smokers (1 point).

Dietary intake

Information was obtained by use of the semiquantitative food-frequency questionnaire (FFQW65) [23, 24]. FFQW65 consists of 65 food items for each meal with colored illustrations showing portion sizes. The recommended dietary allowance (RDA) was calculated on the basis of the individual's height and unit kilocalorie (usually 25-30 kcal), which was defined by physical activity level based on occupation, and age. Then, the following "overintake/underintake fraction" was used to measure the individual's status of dietary intake: (actual total energy intake/RDA-1) $\times 100 \%$. Absolute values of the "overintake/underintake fraction" for breakfast, lunch, and supper in addition to daily fraction were calculated by use of this equation $[23,24]$.

\section{Statistical analysis}

Concurrence of weight gain (an increase in BMI more than $0.8 \mathrm{~kg} / \mathrm{m}^{2}$ ) and psychological deterioration (an increase in GHQ-12 score more than one point) before and after the fiveyear follow-up period was analyzed using the McNemar's chi-squared test. The scores from psychological factors including SOC, stress score, and HLC and lifestyle variables at baseline were compared between two groups; workers who increased BMI by more than $0.8 \mathrm{~kg} / \mathrm{m}^{2}$ and those who did not after the five-year follow-up, using Student's $t$ test. Likewise, categorizing the workers in two groups, those who showed an increase in GHQ-12 score of more than one point and those who did not, we compared the psychological and lifestyle variables at baseline between these two groups, using Student's $t$ test. Multiple logistic regression analysis was performed for two groups with psychological and lifestyle variables as the independent variables. Because lifestyle variables were considered to be a nominal scale, the distributions of workers were compared among the categories of lifestyle factors between the two groups using the chi-squared test. All statistical tests were two-tailed. SPSS (Ver 11) was used for all statistical analysis. $p$ values less than 0.05 were regarded as indicating statistical significance.

\section{Results}

During the five-year follow-up period, we recognized that 21 workers showed an increase in BMI of more than $0.8 \mathrm{~kg} / \mathrm{m}^{2}$. In the same period, the GHQ-12 scores elevated more than one point in 37 workers. Concurrence of increased body weight and GHQ-12 score was observed in 15 workers. McNemar's chi-squared test showed significant concurrence of increased body weight and GHQ-12 score (chi-squared value, 8.04; $p<0.01$ ).

Psychological factors including SOC, stress scores, HLC (Table 1), and lifestyle factors including exercise, alcohol, smoking, BMI, and dietary intake (Table 2) at baseline were compared between workers who increased weight 
(BMI) and those who did not after five-year follow-up. Student's $t$ test showed that significantly lower SOC score, higher stress score (Table 1), higher score of frequency of exercise, and higher absolute value of the "overintake/ underintake fraction" for total energy intake (\%) for supper (Table 2) were recognized in workers who increased BMI compared with those who did not. Figure 1 shows the number of workers according to exercise frequency and smoking status at baseline. Significant differences in the distribution of exercise frequency and smoking status were observed between two groups-workers for whom psychological well-being was worse (an increase in GHQ-12) and those for whom it was not worse, after five-year follow-up.

Likewise, Student's $t$ test demonstrated that an elevation of GHQ-12 score, indicating poorer psychological wellbeing, was significantly associated with the low SOC sore (Table 3), low frequency of exercise, high-smoking score, and high-dietary intake at supper (Table 4).

Multiple logistic regression analysis showed that low SOC, low CHLC, high FHLC, low frequency of exercise, and high-supper intake were significantly associated with weight (BMI) increase (Table 5), and that low SOC, low frequency of exercise, high-smoking score, and high-supper intake significantly contributed to poorer psychological well-being (an increase in GHQ-12; Table 6).

To summarize the univariate and multivariate analyses, low SOC, low frequency of exercise, and high-dietary intake at supper may be common risk factors underlying the development of obesity and poorer psychological wellbeing in workers.

\section{Discussion}

Our results showed concurrence of development of weight gain and poor psychological well-being in middle-aged workers. Indeed, until recently little consideration was given to the possibility that metabolic dysregulation might influence brain function [12]. In this study, therefore, we tried to examine risk factors common to weight gain and deterioration of psychological well-being in relatively elderly workers. Our previous cross-sectional study on psychological, behavioral, and physical problems in workers suggests that low SOC score, low frequency of exercise, high-smoking frequency, and high BMI significantly contributed to high-GHQ-12 score in relatively elder workers [11]. However, it is very much noteworthy that the risk factors which we extracted in this study were not only for high GHQ-12, but also for weight gain in middle-aged workers. In this study, univariate and multivariate analysis indicated that low SOC, low frequency of exercise, and high-dietary intake at supper concurrently 
Table 2 Comparison of life-style factors including dietary intake at baseline between workers who increased weight (BMI) and those who did not after five-year follow-up

\begin{tabular}{|c|c|c|c|c|c|c|c|c|}
\hline \multirow[t]{2}{*}{ BMI group } & \multirow[t]{2}{*}{$\begin{array}{l}\text { Number } \\
\text { of workers }\end{array}$} & \multicolumn{3}{|c|}{ Value (mean $\pm \mathrm{SD}$ ) } & \multicolumn{4}{|c|}{$\begin{array}{l}\text { Absolute value of the "overintake/underintake fraction" } \\
(\text { mean } \pm \mathrm{SD})\end{array}$} \\
\hline & & Exercise (score) ${ }^{\mathrm{a}}$ & Alcohol (score) & Smoking (score) & Breakfast $(\%)$ & Lunch $(\%)$ & Supper (\%) & Daily (\%) \\
\hline No increase & 89 & $1.18 \pm 0.386$ & $1.17 \pm 0.376$ & $1.38 \pm 0.489$ & $23.9 \pm 2.89$ & $15.3 \pm 4.24$ & $58.8 \pm 7.14$ & $21.4 \pm 3.40$ \\
\hline Increase & 21 & $1.76 \pm 0.436^{* * *}$ & $1.19 \pm 0.402$ & $1.52 \pm 0.512$ & $22.3 \pm 1.76$ & $14.5 \pm 3.33$ & $65.2 \pm 5.90^{*}$ & $22.4 \pm 2.21$ \\
\hline
\end{tabular}

Statistical analysis of differences was performed by use of Student's $t$ test. Statistically significant difference compared with the value for workers who did not increased weight (BMI), $* p<0.05, * * * p<0.001$

${ }^{\text {a }}$ The responses to the physical exercise frequency were classified as never (less than one day, 2 points), a few days (2-3 days, 1 point), and always (more than four days, 1 point) per week

contributed to subsequent body weight gain together with deterioration of psychological well-being in older workers. SOC, a candidate as a mediating stress factor, is studied in the framework of Antonovsky's salutogenesis paradigm, which emphasizes the origin of health [25-28]. Life event stressors, depression, anxiety, and working conditions, particularly work stressors, influence levels of SOC [26, 29-31]. Takayama et al. [32] showed that SOC is positively related to psychological health, which suggests the buffering effect of SOC on the maintenance of normal psychological health in dealing with stressful life events. We have previously demonstrated that SOC may be an important psychological modifier for determining lifestyle, including exercise and dietary habits [33], smoking behavior [34], and reaction to job stress [35]. Taken together with such a close relationship between SOC and stress coping, our results imply that inappropriate stress coping leads to body weight gain and to poorer psychological well-being. Although life stress event and job stress including SOC are important risk factors for poor psychological well-being [11, 33, 34, 36], our finding that low SOC leads to subsequent body weight gain in older workers is very striking. The cohort study followed-up over 14 years by Chandola et al. [8, 37], who examined cumulative work stress, using the Job Strain Questionnaire on four occasions, as a predictor of obesity in a prospective 19-year study of 6,895 men and 3,413 women (aged 3555 years) in the Whitehall II cohort in London, UK (baseline: 1985-1988), reported a dose-response relationship between work stress and risk of general obesity (BMI $30 \mathrm{~kg} / \mathrm{m}^{2}$ ). Plausible pathophysiological mechanisms in stress-induced weight gain involve direct neuroendocrine effects and indirect effects mediated by adverse health behavior, including changes in eating habits [1], exercise frequency [38], sleep [39], social gradient [40, 41], and psychosocial resources [42]. Chronic psychological stress may reduce biological resilience and thus disturb homoeostasis [43] by chronic hyperactivation of the hypothalamic pituitary-adrenal axis or increased adipocyte secretion of adipokines, which favors accumulation of

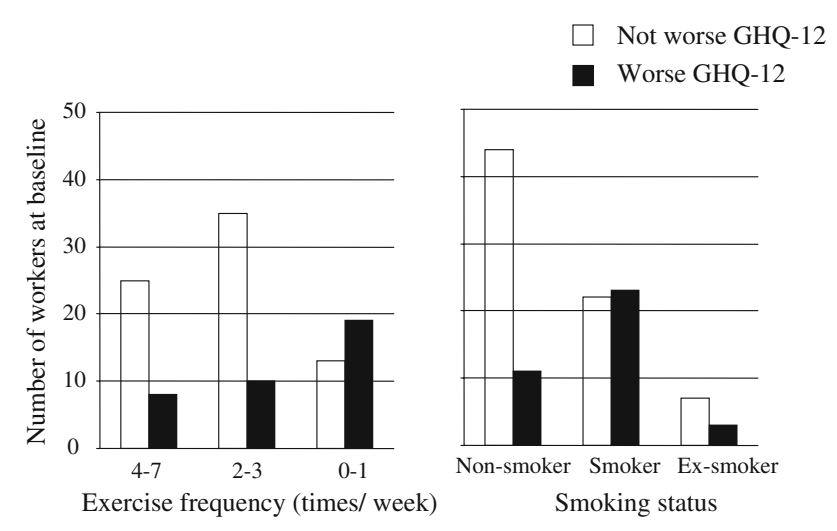

Fig. 1 Numbers of workers according to exercise frequency $(l e f t)$ and smoking status (right) at baseline. The chi-squared test showed significant difference in the distribution of exercise frequency $(p<0.01)$ and smoking status $(p<0.01)$ between two groupsworkers for whom psychological well-being became worse (an increase in GHQ-12) and those for whom it did not after five-year follow-up

visceral fat, and vice versa [7, 13]. On the basis of an association between job stress and overweight [37, 44], therefore, low SOC, which implies difficulty in coping with stress, is likely to be an important risk factor not only for deterioration of psychological well-being but also for development of overweight.

Low frequency of exercise was extracted as a predictor of poorer psychological well-being and weight gain, because physical activity may have beneficial effects not only on physical health [45] such as preventing obesity [38, 46], but also on mental health [47, 48]. Peterson and Dunnagen [49] reported that regular exercise was found to promote job-satisfaction. Because considering the mental health condition of elderly workers is very important problem [10, 11], we must focus on a further intervention study in which exercise should be incorporated in a health educational program for workers.

Needless to say, intake of high-calorie diets results in greater weight gain [50,51], whereas it is very noteworthy that our results showed that it reduced psychological 
Table 3 Comparison of psychological factors at baseline between workers for whom psychological well-being became worse (an increase in GHQ-12) and those for whom it did not after five-year follow-up

\begin{tabular}{|c|c|c|c|c|c|c|c|c|c|}
\hline \multirow[t]{2}{*}{ GHQ group } & \multirow{2}{*}{$\begin{array}{l}\text { Number of } \\
\text { workers }\end{array}$} & \multicolumn{3}{|c|}{ Value (mean $\pm \mathrm{SD})$} & \multicolumn{5}{|c|}{ Value of health locus of control (mean $\pm \mathrm{SD}$ ) } \\
\hline & & Age (years) & SOC (score) & $\begin{array}{l}\text { Stress } \\
\text { (score) }\end{array}$ & $\begin{array}{l}\text { SHLC } \\
\text { (score) }\end{array}$ & $\begin{array}{l}\text { IHLC } \\
\text { (score) }\end{array}$ & $\begin{array}{l}\text { CHLC } \\
\text { (score) }\end{array}$ & $\begin{array}{l}\text { FHLC } \\
\text { (score) }\end{array}$ & $\begin{array}{l}\text { PHLC } \\
\text { (score) }\end{array}$ \\
\hline Not worse & 73 & $52.6 \pm 2.85$ & $130.0 \pm 16.1$ & $28.2 \pm 4.45$ & $11.6 \pm 4.87$ & $24.7 \pm 3.27$ & $15.1 \pm 5.02$ & $21.7 \pm 3.96$ & $19.0 \pm 4.52$ \\
\hline Worse & 37 & $52.2 \pm 2.55$ & $117.9 \pm 15.5^{* * *}$ & $29.9 \pm 5.76$ & $11.8 \pm 4.70$ & $24.4 \pm 3.22$ & $14.0 \pm 4.21$ & $21.1 \pm 3.70$ & $18.9 \pm 4.02$ \\
\hline
\end{tabular}

Statistical analysis of differences was performed by use of Student's $t$ test. Statistically significant differences compared with the value for workers who did not increase weight (BMI), $* * * p<0.001$

Table 4 Comparison of life-style factors, including dietary intake at baseline, between workers over 40 years old for whom psychological wellbeing became worse (an increase in GHQ-12) and those for whom it did not after five-year follow-up

\begin{tabular}{|c|c|c|c|c|c|c|c|c|c|}
\hline \multirow[t]{2}{*}{$\begin{array}{l}\text { GHQ } \\
\text { group }\end{array}$} & \multirow[t]{2}{*}{$\begin{array}{l}\text { Number of } \\
\text { workers }\end{array}$} & \multicolumn{4}{|c|}{ Value (mean $\pm \mathrm{SD}$ ) } & \multicolumn{4}{|c|}{$\begin{array}{l}\text { Absolute value of the "overintake/underintake fraction" } \\
(\text { mean } \pm \mathrm{SD})\end{array}$} \\
\hline & & $\begin{array}{l}\text { Exercise } \\
(\text { score })^{\mathrm{a}}\end{array}$ & $\begin{array}{l}\text { Alcohol } \\
\text { (score) }\end{array}$ & $\begin{array}{l}\text { Smoking } \\
\text { (score) }\end{array}$ & $\begin{array}{l}\text { BMI } \\
\text { (score) }\end{array}$ & $\begin{array}{l}\text { Breakfast } \\
(\%)\end{array}$ & $\begin{array}{l}\text { Lunch } \\
(\%)\end{array}$ & $\begin{array}{l}\text { Supper } \\
(\%)\end{array}$ & $\begin{array}{l}\text { Daily } \\
(\%)\end{array}$ \\
\hline Not worse & 73 & $1.18 \pm 0.385$ & $1.19 \pm 0.396$ & $1.30 \pm 0.462$ & $23.4 \pm 2.92$ & $25.3 \pm 2.36$ & $15.7 \pm 4.00$ & $57.9 \pm 7.11$ & $21.9 \pm 2.54$ \\
\hline Worse & 37 & $1.51 \pm 0.507 * *$ & $1.14 \pm 0.347$ & $1.62 \pm 0.492 * *$ & $23.0 \pm 2.49$ & $25.6 \pm 2.10$ & $14.1 \pm 4.07$ & $64.1 \pm 6.02 * * *$ & $20.9 \pm 4.24$ \\
\hline
\end{tabular}

Statistical analysis of differences was performed by use of Student's $t$ test. Statistically significant difference compared with the value for workers who did not increase weight (BMI), ${ }^{*} p<0.05, * * p<0.01, * * * p<0.001$

${ }^{a}$ The responses to the physical exercise frequency were classified as never (less than one day, 2 points), a few days (2-3 days, 1 point), and always (more than four days, 1 point) per week

Table 5 Multiple logistic regression analysis for weight increase (BMI) using SOC, stress, GHQ-12, health locus of control, and life-style factors at baseline as explanatory variables for workers

\begin{tabular}{|c|c|c|c|c|c|}
\hline Variable & $\begin{array}{l}\text { Regression } \\
\text { coefficient }\end{array}$ & SE & $p$ value & Odds ratio & 95\% Confidence interval \\
\hline Age ( $\geq$ vs $<53$ years old) & 0.179 & 0.189 & 0.343 & 1.2 & $0.826-1.73$ \\
\hline SOC ( $\geq 126$ vs $<126$ points $)$ & -0.120 & 0.042 & $0.004 *$ & 0.886 & $0.816-0.960$ \\
\hline Stress ( $\geq 29$ vs $<29$ points) & 0.136 & 0.093 & 0.142 & 1.15 & $0.955-1.37$ \\
\hline GHQ-12 ( $\geq 2$ vs $<2$ points) & -0.692 & 0.463 & 0.135 & 0.501 & $0.202-1.24$ \\
\hline SHLC ( $\geq 12$ vs $<12$ points) & -0.066 & 0.118 & 0.577 & 0.936 & $0.742-1.18$ \\
\hline IHLC ( $\geq 25$ vs $<25$ points) & 0.010 & 0.136 & 0.940 & 1.01 & $0.774-1.32$ \\
\hline CHLC ( $\geq 15$ vs $<15$ points) & -0.283 & 0.136 & $0.037 *$ & 0.754 & $0.577-0.980$ \\
\hline FHLC ( $\geq 22$ vs $<22$ points) & 0.378 & 0.187 & $0.043 *$ & 1.46 & $1.01-2.11$ \\
\hline PHLC ( $\geq 19$ vs $<19$ points) & 0.255 & 0.134 & 0.056 & 1.29 & $0.993-1.68$ \\
\hline Exercise ( $0-1$ vs $2-7$ times per week) & 4.11 & 1.22 & $0.001 * *$ & 61.0 & $5.60-665.5$ \\
\hline Alcohol (every day vs not every day) & -1.257 & 1.42 & 0.376 & 0.285 & $0.018-4.59$ \\
\hline Smoking (current smoker vs non-smoker) & -0.434 & 0.916 & 0.636 & 0.648 & $0.108-3.90$ \\
\hline Breakfast ( $\geq 26$ vs $<26 \%$ ) & -0.445 & 0.300 & 0.138 & 0.641 & $0.356-1.15$ \\
\hline Lunch $(\geq 16$ vs $<16 \%)$ & -0.052 & 0.158 & 0.743 & 0.95 & $0.697-1.29$ \\
\hline Supper $(\geq 60$ vs $<60 \%$ ) & 0.227 & 0.114 & $0.047 *$ & 1.25 & $1.00-1.57$ \\
\hline Daily ( $\geq 21$ vs $<21 \%$ ) & 0.381 & 0.190 & $0.045^{*}$ & 1.46 & $1.01-2.12$ \\
\hline
\end{tabular}

$* p<0.05, * * p<0.01$

well-being in middle-aged workers. Under stress, most people show a tendency to take more sweet and fatty foods than protein-rich foods, which may be part of a coping response [52]. This explains well our findings that workers with low SOC, who are unable to cope with stress well, increased their weight. However, multiple regression analysis recognized a significant contribution of higher dietary intake to the subsequent poorer psychological well- 
Table 6 Multiple logistic regression analysis for development of worse psychological well-being (an increase in GHQ-12) using SOC, stress, health locus of control, and life-style factors at baseline as explanatory variables for workers

\begin{tabular}{|c|c|c|c|c|c|}
\hline Variable & $\begin{array}{l}\text { Regression } \\
\text { coefficient }\end{array}$ & SE & $p$ value & Odds ratio & $\begin{array}{l}95 \% \text { Confidence } \\
\text { interval }\end{array}$ \\
\hline Age ( $\geq$ vs $<53$ years old $)$ & -0.140 & 0.115 & 0.223 & 0.869 & $0.693-1.09$ \\
\hline SOC ( $\geq 126$ vs $<126$ points $)$ & -0.055 & 0.024 & $0.023 *$ & 0.947 & $0.903-0.993$ \\
\hline Stress ( $\geq 29$ vs $<29$ points) & 0.048 & 0.073 & 0.514 & 1.05 & $0.909-1.21$ \\
\hline SHLC ( $\geq 12$ vs $<12$ points) & -0.058 & 0.077 & 0.449 & 0.943 & $0.812-1.10$ \\
\hline IHLC ( $\geq 25$ vs $<25$ points) & -0.114 & 0.090 & 0.204 & 0.892 & $0.748-1.06$ \\
\hline CHLC ( $\geq 15$ vs $<15$ points) & -0.108 & 0.082 & 0.187 & 0.897 & $0.764-1.05$ \\
\hline FHLC ( $\geq 22$ vs $<22$ points) & -0.066 & 0.085 & 0.440 & 0.936 & $0.792-1.11$ \\
\hline PHLC ( $\geq 19$ vs $<19$ points) & 0.055 & 0.076 & 0.469 & 1.06 & $0.910-1.23$ \\
\hline Exercise (0-1 vs $2-7$ times per week) & 2.09 & 0.728 & $0.004 * *$ & 8.09 & $1.94-33.7$ \\
\hline Alcohol (every day vs not every day) & -0.620 & 0.880 & 0.481 & 0.538 & $0.096-3.02$ \\
\hline Smoking (current smoker vs non-smoker) & 1.45 & 0.640 & $0.024 *$ & 4.25 & $1.21-14.9$ \\
\hline BMI (over vs under $24 \mathrm{mg} / \mathrm{m}^{2}$ ) & -0.193 & 0.114 & 0.092 & 0.825 & $0.659-1.03$ \\
\hline Breakfast $(\geq 26$ vs $<26 \%$ ) & -0.064 & 0.166 & 0.699 & 0.938 & $0.678-1.30$ \\
\hline Lunch $(\geq 16$ vs $<16 \%)$ & -0.116 & 0.110 & 0.292 & 0.89 & $0.717-1.11$ \\
\hline Supper $(\geq 60$ vs $<60 \%)$ & 0.132 & 0.062 & $0.033^{*}$ & 1.14 & $1.01-1.29$ \\
\hline Daily $(\geq 21$ vs $<21 \%$ ) & -0.174 & 0.113 & 0.123 & 0.841 & $0.674-1.05$ \\
\hline
\end{tabular}

${ }^{*} p<0.05,{ }^{* *} p<0.01$

being. Therefore, excessive intake of calories may, by itself, lead to deterioration of psychological well-being in workers. Accumulating data suggest that meal size and frequency can affect mental health [53]. Ishihara et al. [54] suggest that maintenance of higher psychological wellbeing (lower GHQ-30) following the six-month lifestyle intervention program is parallel to good lifestyle such as low calorie intake. Therefore, our results are likely to support the belief that calorie restriction may improve psychological well-being in middle-aged workers, although we must evaluate daily calorie intake more objectively in a future study.

\section{Conclusion}

Our five-year follow-up study of 110 male office workers showed concurrence of weight gain and poorer psychological well-being in middle-aged workers. Univariate and multivariate analysis showed that a low SOC score, a low frequency of exercise, and a high-dietary intake at supper were significantly associated with both weight gain and poor psychological well-being in workers. Exercise and calorie restriction seem to prevent weight gain and promote psychological well-being in older workers. Low SOC, which implies difficulty in coping with stress, is likely to be an important risk factor not only for deterioration of psychological well-being, but also body weight gain. These hypotheses must be addressed in future intervention studies on SOC and lifestyle including exercise and eating behavior.

Acknowledgments This work was supported in part by a grant-inaid for Scientific Research from the Japanese Foundation for Occupational Health Promotion in 2003-2006.

\section{References}

1. Tamashiro KL, Hegeman MA, Sakai RR. Chronic social stress in a changing dietary environment. Physiol Behav. 2006;89(4):53642.

2. Procopiou M, Philippe J. The metabolic syndrome and type 2 diabetes: epidemiological figures and country specificities. Cerebrovasc Dis. 2005;20(Suppl 1):2-8.

3. Flegal KM, Graubard BI, Williamson DF, Gail MH. Excess deaths associated with underweight, overweight, and obesity. JAMA. 2005;293(15):1861-7.

4. Visscher TL, Rissanen A, Seidell JC, Heliovaara M, Knekt P, Reunanen A, et al. Obesity and unhealthy life-years in adult Finns: an empirical approach. Arch Intern Med. 2004;164(13): 1413-20.

5. Hu FB, Li TY, Colditz GA, Willett WC, Manson JE. Television watching and other sedentary behaviors in relation to risk of obesity and type 2 diabetes mellitus in women. JAMA. 2003;289(14):1785-91.

6. Schulze MB, Manson JE, Ludwig DS, Colditz GA, Stampfer MJ, Willett WC, et al. Sugar-sweetened beverages, weight gain, and incidence of type 2 diabetes in young and middle-aged women. JAMA. 2004;292(8):927-34.

7. Kyrou I, Chrousos GP, Tsigos C. Stress, visceral obesity, and metabolic complications. Ann N Y Acad Sci. 2006;1083:77-110. 
8. Brunner EJ, Chandola T, Marmot MG. Prospective effect of job strain on general and central obesity in the Whitehall II Study. Am J Epidemiol. 2007;165(7):828-37.

9. Rosenstock L. Work organization research at the National Institute for occupational safety and health. J Occup Health Psychol. 1997;2(1):7-10.

10. Harma M, Kandolin I. Shiftwork, age and well-being: recent developments and future perspectives. J Hum Ergol (Tokyo). 2003;40(2):287-93.

11. Matsuzaki I, Sagara T, Oshita Y, Nagase H, Ogino K, Sasahara S, et al. Psychological factors including sense of coherence and some lifestyles are related to General Health Questionnaire-12 (GHQ-12) in elderly workers in Japan. Environ Health Prevent Med. 2007;12:21-7.

12. Hendrickx H, McEwen BS, Ouderaa F. Metabolism, mood and cognition in aging: the importance of lifestyle and dietary intervention. Neurobiol Aging. 2005;26(Suppl 1):1-5.

13. Kyrou I, Tsigos C. Stress mechanisms and metabolic complications. Horm Metab Res. 2007;39(6):430-8.

14. Elias MF, Elias PK, Sullivan LM, Wolf PA, D’Agostino RB. Obesity, diabetes and cognitive deficit: the Framingham Heart Study. Neurobiol Aging. 2005;26(Suppl 1):11-6.

15. Doi Y, Minowa M. Factor structure of the 12 -item General Health Questionnaire in the Japanese general adult population. Psychiatry Clin Neurosci. 2003;17(4):379-83.

16. Fuchino Y, Mizoue T, Tokui N, Ide R, Fujino Y, Yoshimura T. Health-related lifestyle and mental health among inhabitants of a city in Japan (in Japanese). Nippon Koshu Eisei Zasshi. 2003; 116(1171):303-13

17. Dahlin L, Cederblad M, Antonovsky A, Hagnell O. Childhood vulnerability and adult invincibility. Acta Psychiatr Scand. 1990;82:228-32.

18. Yamazaki Y. SOC, a theory on salutogenesis and health promoting ability from newly developed view points for health (in Japanese). Quality Nursing. 1999;5:824-32.

19. Cohen S, Kamarck T, Mermelstein R. A global measure of perceived stress. J Health Soc Behav. 1983;24:385-96.

20. Cohen S, Tyrrell DA, Smith AP. Psychological stress and susceptibility to the common cold. N Engl J Med. 1991;325:606-12.

21. Horige Y. A Japanese version of the Health Locus of Control Scales (in Japanese). Kenko Shinri Kenkyu. 1991;4:1-7.

22. Wallston KA, Wallston BS, DeVellis R. Development of the Multidimensional Health Locus of Control (MHLC) Scales. Health Educ Monogr. 1978;6:160-70.

23. Yamaoka K, Tango T, Watanabe M, Yokotsuka M. Validity and reproducibility of a semi-quantitative food frequency questionnaire for nutritional education of patients of diabetes mellitus (FFQW65) (in Japanese). Nippon Koshu Eisei Zasshi. 2000;47(3):230-44.

24. Watanabe M, Yamaoka K, Yokotsuka M, Tango T. Randomized controlled trial of a new dietary education program to prevent type 2 diabetes in a high-risk group of Japanese male workers. Diabetes Care. 2003;26(12):3209-14.

25. Antonovsky A. The life cycle, mental health and the sense of coherence. Isr J Psychiatry Relat Sci. 1985;22(4):273-80.

26. Antonovsky H, Sagy S. The development of a sense of coherence and its impact on responses to stress situations. J Soc Psychol. 1986;126(2):213-25.

27. Antonovsky A. The structure and properties of the sense of coherence scale. Soc Sci Med. 1993;36(6):725-33.

28. Antonovsky A. The moral and the healthy: identical, overlapping or orthogonal? Isr J Psychiatry Relat Sci. 1995;32(1):5-13.

29. Flannery RB Jr, Perry JC, Penk WE, Flannery GJ. Validating Antonovsky's sense of Coherence Scale. J Clin Psychol. 1994;50(4):575-7.

30. Bernstein J, Carmel S. Trait anxiety and the sense of coherence. Psychol Rep. 1987;60(3 PT 1):1000.
31. Flannery RB Jr, Flannery GJ. Sense of coherence, life stress, and psychological distress: a prospective methodological inquiry. J Clin Psychol. 1990;46(4):415-20.

32. Takayama T, Asano Y, Yamazaki Y, Yoshii K, Nagasaka Y, Fukada J, et al. Sense of coherence, stressful life events and psychological health. Nippon Koshu Eisei Zasshi. 1999;49(444): 965-76.

33. Nakamura H, Matsuzaki I, Sasahara S, Hatta K, Nagase H, Oshita $\mathrm{Y}$, et al. Enhancement of a sense of coherence and natural killer cell activity which occurred in subjects who improved their exercise habits through health education in the workplace. J Occup Health. 2003;45(5):278-85.

34. Nakamura H, Ogawa $\mathrm{Y}$, Nagase H, Nakajima M, Kodama N, Ogino $\mathrm{K}$, et al. Natural killer cell activity and its related psychological factor, sense of coherence in male smokers. J Occup Health. 2001;43:191-8.

35. Kivimaki M, Kalimo R, Toppinen S. Sense of coherence as a modifier of occupational stress exposure, stress perception, and experienced strain: a study of industrial managers. Psychol Rep. 1998;83(3 PT 1):971-81.

36. Flensborg-Madsen T, Ventegodt S, Merrick J. Sense of coherence and physical health. A review of previous findings. Sci World J. 2005;5:665-73.

37. Chandola T, Brunner E, Marmot M. Chronic stress at work and the metabolic syndrome: prospective study. BMJ. 2006; 332(7540):521-5.

38. Tsatsoulis A, Fountoulakis S. The protective role of exercise on stress system dysregulation and comorbidities. Ann N Y Acad Sci. 2006;1083:196-213.

39. Mikurube H, Kaneko M, Murata C, Komaki Y, Ishikawa N, Higashiyama R, et al. Association of change in the type of job with prevalence of components of the metabolic syndrome-special reference to job stress (in Japanese). Nippon Koshu Eisei Zasshi. 2005;52(11):987-93.

40. Hemingway H, Shipley M, Brunner E, Britton A, Malik M, Marmot $\mathrm{M}$. Does autonomic function link social position to coronary risk? The Whitehall II study. Circulation. 2005;111(23):3071-7.

41. Prescott E, Godtfredsen N, Osler M, Schnohr P, Barefoot J. Social gradient in the metabolic syndrome not explained by psychosocial and behavioural factors: evidence from the Copenhagen City Heart Study. Eur J Cardiovasc Prev Rehabil. 2007;14(3):405-12.

42. Gallo LC, de Los Monteros KE, Ferent V, Urbina J, Talavera G. Education, psychosocial resources, and metabolic syndrome variables in latinas. Ann Behav Med. 2007;34(1):14-25.

43. Vrijkotte TG, van Doornen LJ, de Geus EJ. Work stress and metabolic and hemostatic risk factors. Psychosom Med. 1999;61(6):796-805.

44. Brunner EJ, Hemingway H, Walker BR, Page M, Clarke P, Juneja $\mathrm{M}$, et al. Adrenocortical, autonomic, and inflammatory causes of the metabolic syndrome: nested case-control study. Circulation. 2002;106(21):2659-65.

45. Blair SN, Kohl HW, Barlow CE, Paffenbarger RS Jr, Gibbons LW, Macera CA. Changes in physical fitness and all-cause mortality. A prospective study of healthy and unhealthy men. JAMA. 1995;273(14):1093-8.

46. Friedenreich CM, Orenstein MR. Physical activity and cancer prevention: etiologic evidence and biological mechanisms. J Nutr. 2002;132(11 SUPPL):3456S-64S

47. Camacho TC, Roberts RE, Lazarus NB, Kaplan GA, Cohen RD. Physical activity and depression: evidence from the Alameda County Study. Am J Epidemiol. 1991;134(2):220-31.

48. Paffenbarger RS Jr, Lee IM, Leung R. Physical activity and personal characteristics associated with depression and suicide in American college men. Acta Psychiatr Scand Suppl. 1994; $377: 16-22$. 
49. Peterson M, Dunnagan T. Analysis of a worksite health promotion program's impact on job satisfaction. J Occup Environ Med. 1998;40(11):973-9.

50. Rolls ET. Understanding the mechanisms of food intake and obesity. Obes Rev. 2007;8(Suppl 1):67-72.

51. Rolls BJ, Roe LS, Beach AM, Kris-Etherton PM. Provision of foods differing in energy density affects long-term weight loss. Obes Res. 2005;13(6):1052-60.
52. Wardle J. Eating behaviour and obesity. Obes Rev. 2007; 8(Suppl 1):73-5.

53. Mattson MP. Energy intake, meal frequency, and health: a neurobiological perspective. Annu Rev Nutr. 2005;25:237-60.

54. Ishihara R, Babazono A, Kame C, Yahiro M, Nishioka K. Relationship between the change of mental health and the improvement of lifestyle and physical health (in Japanese). Nippon Eiseigaku Zasshi. 2005;60(4):442-9. 